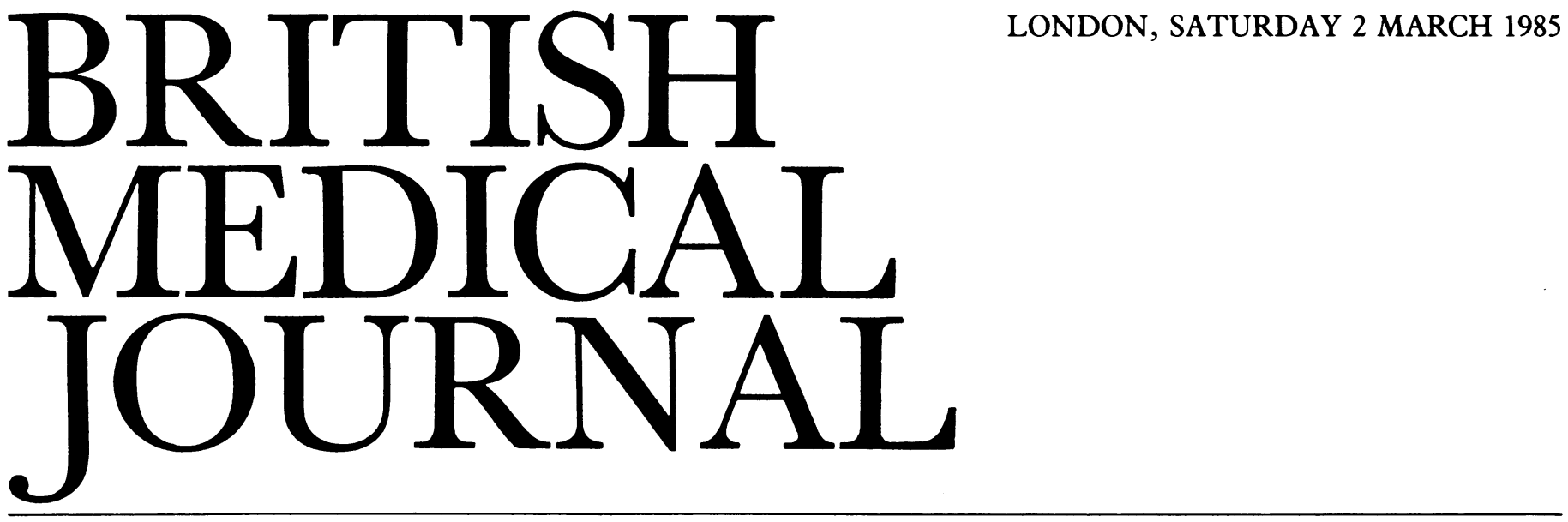

\title{
Pros and cons of continuous subcutaneous insulin infusion
}

Developments in the treatment of diabetes in the past decade, many of them initiated in Britain, have encouraged the introduction by the British Diabetic Association of a new journal-Diabetic Medicine. Appropriately, its first issue includes a symposium on continuous subcutaneous insulin infusion, first described at Guy's Hospital in 1978.

Continuous subcutaneous insulin infusion now has an established place in the treatment of diabetes. By providing continuous basal insulin infusion with preprandial boosts it aims at mimicking the physiological patterns of plasma insulin concentration more closely than those obtained with intermittent insulin injections. Administration of insulin by intraperitoneal infusion is theoretically even more physiological, since at least some of the insulin is delivered intraportally, but this technique is still experimental.

The chief benefit of continuous subcutaneous insulin infusion is the considerable improvement in lifestyle enjoyed by some patients. Blood glucose control is generally improved at the same time. ${ }^{2}$ There is only slender evidence that continuous subcutaneous insulin infusion has any beneficial effect on diabetic complications and no clear proof of harmful effects. Its disadvantages include the relative bulkiness of the apparatus, the risk of mechanical failures, obvious difficulties with vigorous physical activities, rapid development of ketoacidosis, some tendency to gain weight, and in some people problems from skin infection. ${ }^{34}$ Continuous subcutaneous insulin infusion does not provide a general solution for "brittle" diabetes ${ }^{5}$ and is not suitable for emotionally or psychiatrically disturbed patients. It has obvious limitations, too, in very young diabetics. ${ }^{6}$ The technique is also very expensive.

But for some patients the improved quality of lifestyle may be very striking. Continuous subcutaneous insulin infusion allows considerable flexibility, especially with regard to timing of meals, with obvious advantages. Sometimes the rise in the early morning blood glucose concentration (the "dawn phenomenon") is diminished with an improved sense of wellbeing.? Problems from severe hypoglycaemia may decrease, but the overall incidence of such episodes is similar to that with conventional treatment. ${ }^{38}$ Even exercise induced hypoglycaemia may cause fewer problems, though reduction of insulin infusion rate may still be needed. ${ }^{3}$

The control of the blood glucose concentration-and so that of haemoglobin $\mathrm{A}_{1}$-is generally improved by continuous subcutaneous insulin infusion, and good control may be maintained for several years with remarkably constant insulin infusion rates. ${ }^{3}$ Similar degrees of control may also be achieved and maintained with conventional insulin treatments, especially if so called "intensified" regimens are used-namely, subcutaneous insulin injections three or four times daily-with regular blood glucose monitoring. ${ }^{9}$ Continuous subcutaneous insulin infusion is not always successful, and optimal control may not be maintained over long periods; it is not the only method for attaining satisfactory control. ${ }^{10}$

There is no substantive published evidence that continuous subcutaneous insulin infusion modifies the development or progression of diabetic complications. Since their usual evolution is over one to three decades no one should be surprised that studies ranging from a few months to two years should not show an effect. Clearly the answer can come only from careful long term observations. Retinopathy has been subjected to the most rigorous examination; it has been neither halted nor reversed though a more optimistic result may be emerging. ${ }^{11-14}$ The development of transient cotton wool spots during the first year of continuous subcutaneous insulin infusion has attracted much comment. They may represent the consequences of a reduction of the excessively high blood flow which could occur when optimal blood glucose control is achieved. ${ }^{15}$ In one study after two years of continuous subcutaneous insulin infusion there was just a suggestion that more eyes had improved and fewer deteriorated than among controls who continued with conventional treatment.$^{14}$ Other tests of retinal function show improvement during continuous subcutaneous insulin infusion. ${ }^{12}$

The effects of continuous subcutaneous insulin infusion on nephropathy and neuropathy have also been examined. Short term studies (generally over a few months) have shown that improved control may lead to a reduction of microalbuminuria, ${ }^{11}$ an increase in peripheral nerve conduction velocities, ${ }^{16}$ and an improvement in vibration perception; the effects on autonomic function were less convincing. ${ }^{17}$ Not all studies have confirmed these early observations. Moreover, the improvement in physiological measurements in the short term, though encouraging, does not necessarily forecast a diminution of the structural damage which may develop in long term diabetes. Established nephropathy is not reversed by continuous subcutaneous insulin infusion, and glomerular filtration continues to decline not only in those with constant proteinuria but also in those at the earlier stage, when proteinuria is still intermittent. ${ }^{18}$

Continuous subcutaneous insulin infusion is not suitable for all patients, and indeed many prefer to remain having conventional treatment. In the big feasibility study in 
progress in Sheffield only one third of insulin treated diabetics wished to attempt continuous subcutaneous insulin infusion, and one third of these abandoned it within a few weeks. ${ }^{19} 21$ Moreover, it may be hazardous. Episodes of ketoacidosis occur more frequently in those treated by continuous subcutaneous insulin infusion than in those having conventional treatment, even when patients have been properly supervised..$^{819}$ The reason is uncertain. Perhaps the subcutaneous reserve is too small to meet increased demands at times of infection or other stresses, however slight.

The introduction of continuous subcutaneous insulin infusion is an important advance. Who should be offered this treatment? The most cautious recommendation would be that the technique is still under evaluation and should be used only in trial conditions. There is no clear indication for continuous subcutaneous insulin infusion in the management of diabetic complications, except perhaps in some cases of painful neuropathy; this aspect of treatment with continuous subcutaneous insulin infusion has still to be examined properly by long term trials. ${ }^{17}$ Continuous subcutaneous insulin infusion has a limited place in planned pregnancies, when even the most conscientious patient may have difficulty with her diabetic control, but during pregnancy continuous subcutaneous insulin infusion generally offers no advantage over conventional treatment, ${ }^{20}$ and babies may still be very large. ${ }^{1921}$ It is clearly unsuitable for those with "brittle" diabetes, who are usually emotionally unstable and for whom continuous subcutaneous insulin infusion offers no advantage. There remains a group of patients who prefer continuous subcutaneous insulin infusion as the treatment of choice and who benefit in ways already described. They must be well motivated, reliable, able to monitor their own blood glucose concentrations regularly, and have access to expert advice day and night.

\section{P J WATKINS}

Consultant Physician,

Diabetic Department,

King's College Hospital,

London SE5 9RS

1 Pickup JC, Keen H, Parsons JA, Alberti KGMM. Continuous subcutaneous insulin infusion: an approach to achieving normoglycaemia. Br Med f 1978;i:204-7.

2 Pickup JC. Pumps in practice: practical aspects of continuous subcutaneous insulin infusion (CSII). Diabetic Medicine 1984;1:27-32.

3 Home PD, Marshall S. Problems and safety of continuous subcutaneous insulin infusion. Diabetic Medicine 1984;1:41-4.

4 Home PD, Capaldo B, Burrin JM, Worth R, Alberti KGMM. A crossover comparison of continuous subcutaneous insulin infusion (CSII) against multiple injections in insulin-
dependent diabetic subjects. Improved control with CSII. Diabetes Care 1982;5:466-71.

5 Pickup JC, Home PD, Bilous RW, Alberti KGMM, Keen H. Management of severely brittle diabetes by continuous subcutaneous and intramuscular insulin infusion: evidence for a defect in subcutaneous insulin absorption. Br Med f 1981;282:347-50.

6 Green SA. Pump therapy in children. Diabetic Medicine 1984;1:44-7.

7 Buysschaert M, Marchand E, Ketelslegers JM, Lambert AE. Comparison of plasma glucose and plasma-free insulin during CSII and intensified conventional insulin therapy. Diabetes Care 1983;6:1-5.

8 Mecklenburg RS, Benson JW, Becker NM, et al. Clinical use of the insulin infusion pump in 100 patients with type 1 diabetes. N Engl I Med 1982;307:513-8.

9 Chiasson JL, Ducros F, Poliquin-Hamet M, Lopez D, Lecavalier L, Hamet P. Continuous subcutaneous insulin infusion (Mill Hill infuser) versus multiple injections (Medi-Jector) in the treatment of insulin dependent diabetes mellitus and the effect of metabolic control on microangiopathy. Diabetes Care 1984;7:331-7.

10 Reeves ML, Seigler DE, Ryan EA, Skyler JS. Glycemic control in insulin dependent diabetes mellitus: comparison of out-patient intensified conventional therapy with continuous subcutaneous insulin infusion. Am $\mathcal{F}$ Med 1982;72:673-80.

11 Kroc Collaborative Study. Blood glucose control and the evolution of diabetic retinopathy and albuminuria. N Engl J Med 1984;311:365-71.

12 Lauritzen T, Frost-Larsen K, Larsen HW, Deckert T, Steno Study Group. Effect of 1 year of near normal blood glucose levels on retinopathy in insulin-dependent diabetics. Lancet 1983;i:200-3.

13 Dahl-Jorgensen K, Hansen KF, Sineland E, Brinckmann-Hansen O, Aagenaes $\emptyset$, Aker Diabetes Group. Long-term strict control in type $\mathbf{I}$ (insulin-dependent) diabetes mellitus: effect on late diabetic complications [Abstract]. Diabetologia 1983;25:149.

14 Lauritzen T, Frost-Larsen K, Larsen HW, Deckert T, Keiding N, Nielsen G. Continuous subcutaneous insulin infusion. Long term strict control in type 1 (insulin-dependent) diabetes mellitus: effect on late diabetic complications. Lancet 1983;i:1445-6.

15 Atherton A, Hill DW, Keen H, Young S, Edwards EJ. The effect of acute hyperglycaemia on the retinal circulation. Diabetologia 1980;18:233-7.

16 Pietri A, Ehle AL, Raskin P. Changes in nerve conduction velocity after six weeks of glucoregulation with portable infusion pumps. Diabetes 1980;29:668-71.
17 Boulton AJM, Drury J, Clarke B, Ward JD. Continuous subcutaneous insulin infusion in the management of painful diabetic neuropathy. Diabetes Care 1982;5:386-90.

18 Viberti GC, Bilous RW, Mackintosh D, Bending JJ, Keen H. Long-term correction of hyperglycaemia and progression of renal failure in insulin-dependent diabetes. $\mathrm{Br} \mathrm{Med} \mathcal{J}$ 1983;286:598-602.

19 Ward JD. Continuous subcutaneous insulin infusion (CSII): therapeutic options. Diabetic Medicine 1984;1:47-50.

20 Potter J, Reckless J, Cullen D. Subcutaneous continuous insulin infusion and control of blood glucose concentration in diabetics in third trimester of pregnancy. $\mathrm{Br} \mathrm{Med} \mathcal{F}$ 1980;280:1099. 101.

21 Knight G, Boulton AJM, Drury J, et al. A feasibility study of the use of continuous sub-cutaneous insulin infusion in a diabetic clinic: patients' choice of treatment. Diabetic Medicine 1984;1: $267-72$

\section{Deaths of athletes}

Recent allegations have been made that several Soviet athletes of the 1950s have died young and that their deaths might be attributable to a history of drug abuse, principally of anabolic steroids. ${ }^{1}$ Comparisons have been made with a similar cohort of American athletes, the implication being that Soviet athletes take drugs and Americans do not and that as a result the Soviets die prematurely.

Few athletes or coaches are prepared even to discuss drug taking for fear of appearing either to connive at it or worse still to condone it. The subject is taboo. During the Pan American games of 1983, however, a very efficient dope testing team found that no fewer than 19 athletes had "ingested a banned substance" and a further 13 chose to leave for home before their events were run rather than face a dope test. The offending athletes came from Argentina, Canada, Chile, Colombia, Cuba, Nicaragua, Puerto Rico, the United States, and Venezuela. Plainly drugs are used by athletes on both sides of the iron curtain-and everybody knows it.

Fear of the possible side effects does not seem to deter athletes, their desire to win at all costs taking precedence over possible complications in the future. The real deterrent is fear of being caught, since it results in temporary exclusion from competition. This has led increasingly to the use of drugs which are more difficult to detect than synthetic anabolic steroids, such as the naturally occurring hormones testosterone and growth hormone. Distinguishing between exogenous and endogenously produced hormones has proved extremely difficult.

Athletes who take drugs do so because they believe their performance will improve. There is some evidence that this is true of anabolic steroids: large doses aid recovery from exercise, thus permitting heavier training schedules. Weight also increases, giving an advantage to strength athletes such as lifters and throwers. ${ }^{2}$ Improvements in running and jumping ability are also claimed, but the evidence is anecdotal. Testosterone is said to help in the same ways, but there is no evidence whatever that growth hormone improves performance. Belief in the magic powers of hormones is often unshakeable-in much the same way as is the common belief, despite good evidence to the contrary, that taking extra vitamins makes a person more healthy.

Death of top flight athletes during competition is very unusual. Sudden death has, however, been recorded in more ordinary people engaged in sporting activities. Twelve deaths occurred over six years among the joggers of Rhode Island, all but one due to coronary artery disease, seven times the expected mortality in a sedentary population. ${ }^{3}$ These and similar fatalities in related sports probably result from cardiac arrhythmias, since there are few other causes of sudden death. Indeed, abnormalities of heart rhythm-for example, heart block and frequent ventricular extrasystoles 